\title{
Emerging antithrombotic agents for thromboprophylaxis, clinical potential and patient considerations
}

This article was published in the following Dove Press journal:

Journal of Blood Medicine

7 July 2010

Number of times this article has been viewed

\section{Lars C Borris}

Department of Orthopedics, Aarhus University Hospital, Aarhus, Denmark
Correspondence: Lars C Borris Department of Orthopedics, Aarhus University Hospital, Nørrebrogade 44, DK-8000, Aarhus, Denmark

$\mathrm{Tel}+45894945 \mathrm{I} 3$

Fax +4589494I20

Email larsborr@rm.dk

\begin{abstract}
Patients undergoing major orthopedic surgery, total hip arthroplasty (THA) and total knee arthroplasty (TKA) are at high risk of venous thromboembolism, manifesting as deep vein thrombosis or pulmonary embolism. The recommended pharmacologic treatment options for thromboprophylaxis after major orthopedic surgery include the vitamin K antagonists (VKAs eg, warfarin), low molecular weight heparins (LMWHs; eg, enoxaparin) and the synthetic pentasaccharide fondaparinux. Most clinics use some kind of thromboprophylaxis routinely. However, due to the frequent need for coagulation monitoring (VKAs) and subcutaneous injections (LMWHs and fondaparinux) barriers exist to prescribing prophylaxis after discharge from hospital. Targeting specific components of the coagulation cascade has yielded several new antithrombotic agents for use as thromboprophylaxis after THA or TKA. Two of these, dabigatran etexilate and rivaroxaban, have already reached the markets in the European Union member states and Canada. Both are administered by the oral route, once-daily fixed dose and without the need to monitor the anticoagulant effect. Whether these new drugs facilitate guideline adherence, particularly in the outpatient settings and thereby improve the overall clinical outcomes remains to be shown.
\end{abstract}

Keywords: dabigatran etexilate, rivaroxaban, thromboprophylaxis, total joint arthroplasty, venous thromboembolism

\section{Introduction}

Patients undergoing major orthopedic surgery, total hip arthroplasty (THA) and total knee arthroplasty (TKA) are at high risk of venous thromboembolism (VTE), manifesting as deep vein thrombosis (DVT) or pulmonary embolism (PE). ${ }^{1}$ Without prophylaxis, $41 \%-85 \%$ of patients may develop DVT (detected by venography), 0.9\%-28\% may develop PE, and $0.1 \%-7.5 \%$ may suffer a fatal PE. ${ }^{1}$ Traditional pharmacologic treatment options for thromboprophylaxis after major orthopedic surgery include the vitamin K antagonists (VKAs; eg, warfarin), unfractionated heparin (UFH), low molecular weight heparins (LMWHs; eg, enoxaparin) and the synthetic pentasaccharide fondaparinux. Adjusted-dose VKA, LMWH or fondaparinux are recommended for patients undergoing THA with a duration of at least 10 days and extended for up to 35 days (grade $1 \mathrm{~A}$ recommendation). For patients undergoing TKA the same regimens are recommended with a duration of at least 10 days (grade $1 \mathrm{~A}$ recommendation) and with extension for up to 35 days (grade $2 \mathrm{~B}$ recommendation). ${ }^{1}$ Most clinics use some kind of thromboprophylaxis routinely. However, due to frequent need for coagulation monitoring (VKAs) and subcutaneous injections (LMWHs and fondaparinux) barriers exist to prescribing prophylaxis after discharge from hospital. ${ }^{2}$ 
In the USA the annual number of primary THAs and TKAs in 2004 was around 700,000 a number which is expected to increase in the future. ${ }^{3}$ By extrapolation, based on the size of the population and anticipating an equal need for these operations in the European Union (EU) the annual number of primary arthroplasties is at least 1.5 million performed in EU and USA; this makes the prophylaxis market very attractive for drug developers. Intensive research has therefore been carried out during the last 10 years with the focus being on finding new antithrombotic compounds. The dominating research philosophy has favored new compounds that can be administered orally at a fixed dose, without a need for coagulation monitoring, and with an inhibitory action on the activated Factor X (FXa) or on thrombin, Factor IIa (FIIa).

\section{Pathogenesis of VTE}

The pathogenesis of VTE was first proposed by the famous German scientist Virchow, and is referred to as Virchow's triad. ${ }^{4}$ According to his triad three independent factors are involved: a) Vascular stasis; b) Endothelial wall damage; and c) Hypercoagulability.

In major orthopedic surgery, damage to the bone marrow which is rich in tissue factor (TF), impaction of bone cement, and stasis during and after the surgical procedure, triggers a substantial local and systemic thrombin generation and activity, due to TF release, that predisposes to thrombus formation at the site of surgery. ${ }^{5}$ The coagulation cascade is shown in Figure 1.
In conjunction with Factor VIIa, TF activates Factor Xa (FXa) directly (the extrinsic pathway); or via propagation of the tenase complex (Factor VIIIa + Factor IXa) on an activated platelet membrane (the intrinsic pathway). ${ }^{6}$ The prothrombinase complex is then formed on the platelet surface and incorporation of FXa into this complex increases the rate of thrombin generation. The thrombin-generating efficacy of the prothrombinase complex is much more pronounced than that of free $\mathrm{FXa}^{7-9}$ and it has been estimated that one molecule of FXa catalyzes the formation of $\sim 1000$ thrombin molecules. ${ }^{6}$ Thus, FXa is the pivotal point in the coagulation cascade because it can be activated both by the extrinsic and intrinsic pathways; furthermore the only function of FXa in the coagulation process is to promote coagulation and to amplify the events.

\section{Indirect and direct FXa inhibition}

UFH and LMWH are indirect FXa inhibitors because they inhibit FXa by potentiation of the natural inhibitory action of antithrombin (AT) that is an endogenous plasma protein (Figure 1). In addition, UFH also has an inhibitory action on several other coagulation factors the most important of which is FIIa, thrombin. LMWH has a more specific inhibitory action on FXa with some differences between the various compounds. Fondaparinux is a synthetic pentasaccharide with the same mode of action as UFH and LMWH, although in contrast to those it acts solely by the AT-mediated inhibition of $\mathrm{FXa}{ }^{10}$ Direct FXa inhibitors do not need AT to inhibit FXa, because

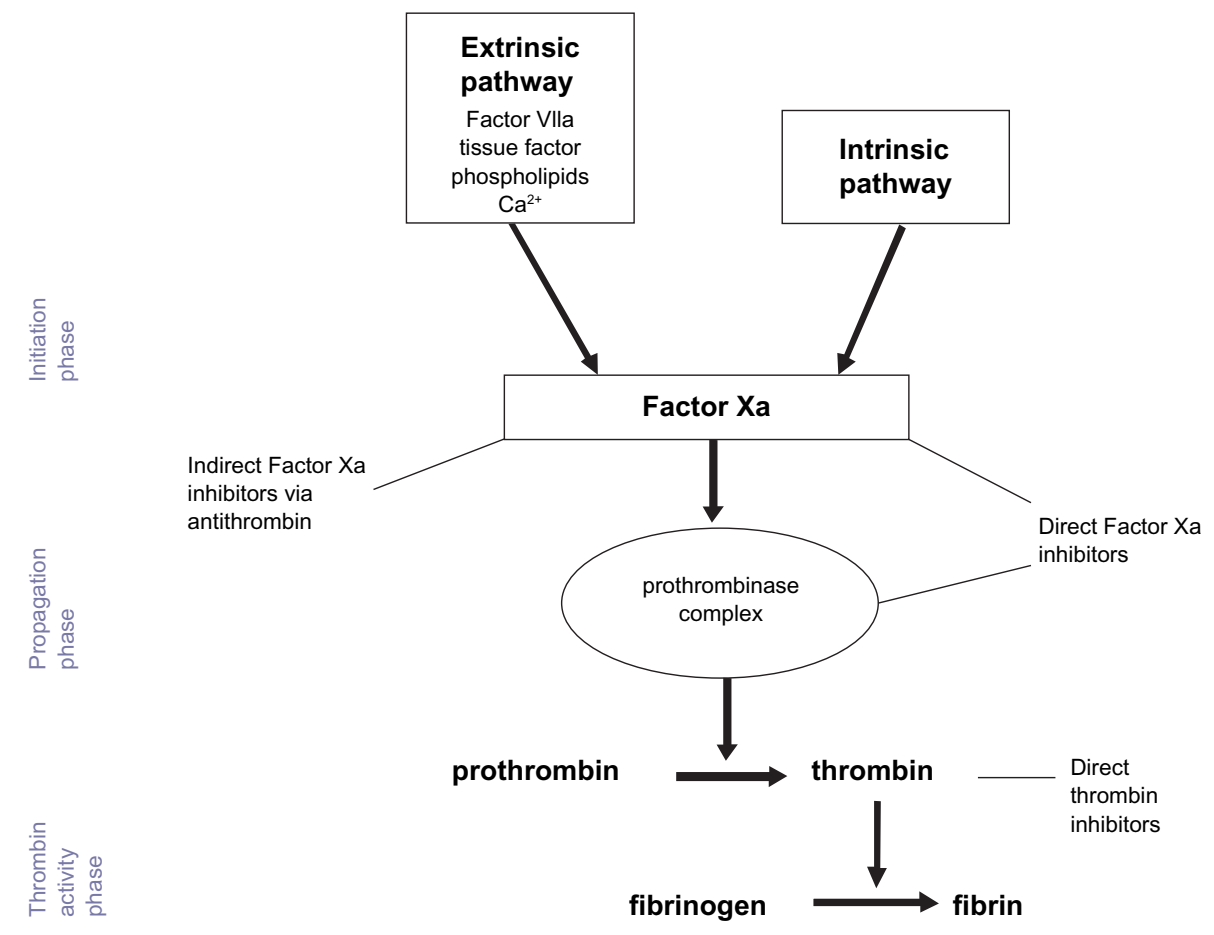

Figure I. The coagulation cascade with indication of the mechanism of action of indirect and direct Factor Xa inhibitors and direct thrombin inhibitors 
they are able to bind directly to the active site of FXa and thereby preventing interaction with its substrates. As a consequence the direct FXa inhibitors are able to inhibit both free FXa and bound FXa in the prothrombinase complex ${ }^{11}$ (Figure 1).

\section{Emerging antithrombotic agents for the prevention of VTE after THA and TKA}

Targeting specific components of the coagulation cascade has yielded several promising new antithrombotic agents with the potential for use as thromboprophylaxis after THA or TKA. The main features of the agents that are in development are summarized in Table 1.

\section{Dabigatran etexilate}

Dabigatran etexilate (Boehringer Ingelheim, International $\mathrm{GmbH}$, Germany) is an oral, once daily (od), direct thrombin inhibitor. It has a rapid onset of action and an estimated half-life of 8-10 hours and 14-17 hours with single- and multiple-dose administration, respectively. Due to its predictable pharmacokinetics (PK) and pharmacodynamics (PD), it is administered at a fixed dose without the need for routine coagulation monitoring. ${ }^{12}$ In patients $<75$ years of age and having normal kidney function the drug is started 1-4 hours after THA with $110 \mathrm{mg}$ and continued with $220 \mathrm{mg}$ od for 28-35 days, in other patients the dosage should be reduced to a starting dose of $75 \mathrm{mg}$ and a continuation dose of $150 \mathrm{mg} .{ }^{13}$ Interactions with other drugs are shown in Table 1.

\section{Clinical documentation}

The phase III RE-NOVATE trial investigated dabigatran etexilate versus enoxaparin for the prevention of VTE after THA in 3,494 patients. ${ }^{14}$ Patients were randomized to receive oral dabigatran etexilate $150 \mathrm{mg}$ or $220 \mathrm{mg}$ od, starting with a half-dose 1-4 hours after surgery, or subcutaneous enoxaparin $40 \mathrm{mg}$ od, starting the evening before surgery, for 28-35 days. The primary efficacy outcome of this study was the zero incidence of VTE and all causes of mortality during treatment. The primary safety outcome was the occurrence of bleeding events during treatment. Major bleeding events were defined as follows: clinically overt bleeding associated with a $\geq 2 \mathrm{~g} / \mathrm{dL}$ fall in hemoglobin; clinically overt bleeding leading to a transfusion of $\geq 2$ units of packed cells or whole blood; fatal, retroperitoneal, intracranial, intraocular, or intraspinal bleeding; or bleeding warranting treatment cessation or leading to re-operation. Both doses of dabigatran etexilate (150 $\mathrm{mg}$ and $220 \mathrm{mg}$ ) were noninferior to enoxaparin $40 \mathrm{mg}$ od $(8.6 \%$ and $6.0 \%$, respectively, versus $6.7 \% ; P<0.0001$ for noninferiority versus enoxaparin) for the primary efficacy outcome. The incidence of major VTE (proximal DVT and PE) was also similar between both doses of dabigatran and enoxaparin (4.3\% and 3.1\%, respectively, versus 3.9\%). Symptomatic DVT occurred in $0.8 \%$ (150 mg) and $0.5 \%$ (220 $\mathrm{mg}$ ) of patients receiving dabigatran, and in $0.1 \%$ of those receiving enoxaparin. The frequency of symptomatic PE was $0.1 \%, 0.4 \%$, and $0.3 \%$ for dabigatran $150 \mathrm{mg}$, $220 \mathrm{mg}$, and enoxaparin, respectively. Major bleeding occurred in $1.3 \%(150 \mathrm{mg})$ and $2.0 \%(220 \mathrm{mg})$ of patients receiving dabigatran etexilate and in $1.8 \%$ of those receiving enoxaparin. The incidence of clinically relevant nonmajor bleeding was $4.7 \%$ and $4.2 \%$ for patients receiving dabigatran $150 \mathrm{mg}$ and $220 \mathrm{mg}$, respectively, compared with $3.5 \%$ for those who received enoxaparin.

Two phase III studies (RE-MODEL and RE-MOBILIZE) for VTE prevention after TKR have also been published. The RE-MODEL study, showed that dabigatran was noninferior to enoxaparin $40 \mathrm{mg}$ od for both safety and efficacy; ${ }^{15}$ however, in the RE-MOBILIZE study both doses of dabigatran (110 mg and $220 \mathrm{mg}$ od) were inferior to the North American regimen of enoxaparin (30 mg twice daily), 34\% and $31 \%$, respectively, versus $25 \%$. ${ }^{16}$ Based on the results of these phase III studies, dabigatran etexilate was approved in 2008 for the prevention of VTE after THA or TKA in all 27 European Union member states and Canada.

\section{Rivaroxaban}

Rivaroxaban (Bayer Schering Pharma AG, Germany; Johnson \& Johnson Pharmaceutical Research and Development, NJ, USA) is an oral od direct FXa inhibitor. ${ }^{17}$ It also inhibits prothrombinase activity, as well as free and clot-associated FXa activity. ${ }^{18,19}$ It has a half-life of 7-11 hours. ${ }^{19,20}$ Rivaroxaban is well tolerated, with a rapid onset of action, reaching peak plasma concentrations within 2 to 4 hours. It has predictable PK and PD, thus can be given at a fixed dose with no need for routine coagulation monitoring. ${ }^{19}$ Additionally, it has no known food-drug or drug-drug interactions in the interaction studies published so far. ${ }^{20-22}$ However, a number of interactions with other drugs are shown in Table 1. Rivaroxaban at a dose of $10 \mathrm{mg}$ is started 6 to 10 hours after surgery and continued od for a total of 5 weeks after THA and 2 weeks after TKA. ${ }^{23}$

\section{Clinical documentation}

Based on the results from phase II studies, a dose of $10 \mathrm{mg}$ od was regarded as an optimal dose in terms of efficacy and safety, and was chosen for the phase III studies. ${ }^{24}$ 


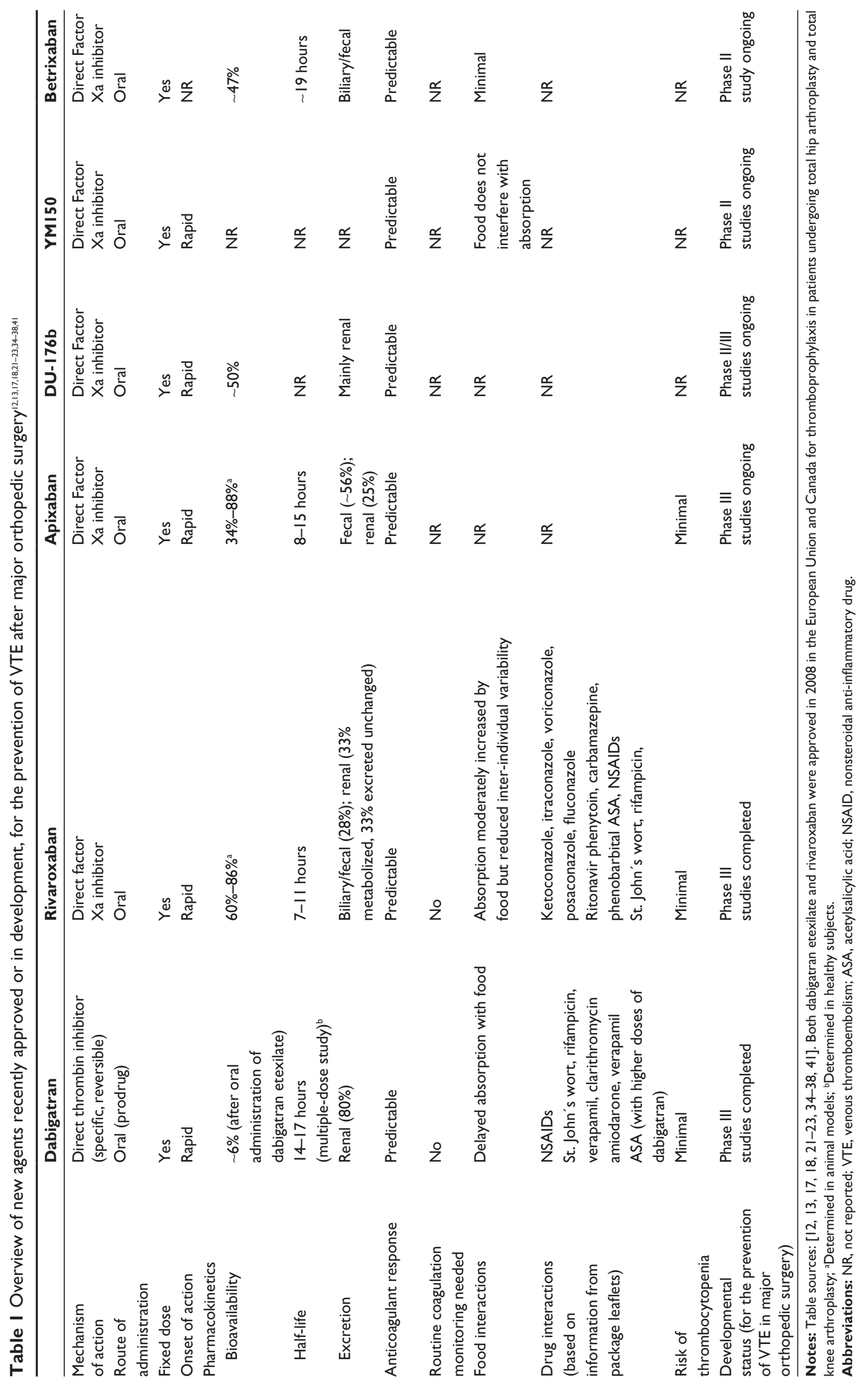


The RECORD program consists of 4 clinical prophylaxis studies presented in Table 2. All studies were prospective, double blind, randomized studies comparing the antithrombotic efficacy and safety of rivaroxaban $10 \mathrm{mg}$ given orally od and enoxaparin $40 \mathrm{mg}$ once daily or $30 \mathrm{mg}$ twice daily in patients undergoing THA or TKA. ${ }^{25-28}$ RECORD 1 and RECORD 2 were performed in THA patients and $40 \mathrm{mg}$ once daily of enoxaparin was used for comparison in both studies. In RECORD 1 both prophylactic regimens were given for a total duration of $35 \pm 4$ days (long-term). In RECORD 2 only rivaroxaban was given long-term when compared with enoxaparin which was only given for 10-14 days (short-term) (Table 3), because it is not universally accepted to use longterm prophylaxis after THA in spite of the recommendation in the ACCP guidelines. ${ }^{1}$ RECORD 3 and RECORD 4 were performed in TKA patients with a treatment duration in both arms of 10-14 days. In RECORD $310 \mathrm{mg}$ of rivaroxaban once daily, started 6-8 hours after surgery, was compared with $40 \mathrm{mg}$ of enoxaparin, started in the evening before surgery. In RECORD 4 enoxaparin $30 \mathrm{mg}$ twice daily started $12-24 \mathrm{~h}$ after surgery was used in the comparator arm (Table 2). The efficacy results of the RECORD studies are presented in Tables 3 and 4 . In all four studies rivaroxaban was significantly more effective in reducing the primary efficacy endpoint, the composite of the incidence of any DVT (proximal and/ or distal), nonfatal symptomatic, objectively confirmed PE and all cause deaths. In RECORD 1-3 also major VTE, the composite of proximal DVT, PE and VTE-related death, was significantly reduced compared with enoxaparin (Table 3). In the RECORD 2 and RECORD 3 studies rivaroxaban also significantly reduced the incidence of symptomatic VTE events compared with enoxaparin (Table 4), which are important observations from a clinical point of view. The primary safety outcome was major bleeding - defined as follows: fatal bleeding; bleeding into a critical organ (eg, retroperitoneal,

Table 2 Design of the double blind, randomized phase III prophylaxis studies in major joint arthroplasty surgery

\begin{tabular}{|c|c|c|c|c|c|}
\hline \multirow[t]{2}{*}{ Study title } & \multirow[t]{2}{*}{ Operation } & \multicolumn{2}{|c|}{ Doses (mg) } & \multicolumn{2}{|c|}{$\begin{array}{l}\text { Duration of } \\
\text { prophylaxis } \\
\text { (days) }\end{array}$} \\
\hline & & riva. & enox. & riva. & enox. \\
\hline RECORD ${ }^{25}$ & THA & 10 od $^{\mathrm{a}}$ & 40 od $^{b}$ & $35 \pm 4$ & $35 \pm 4$ \\
\hline RECORD $2^{26}$ & THA & 10 od $^{\mathrm{a}}$ & 40 od $^{\mathrm{b}}$ & $35 \pm 4$ & $10-14$ \\
\hline RECORD $3^{27}$ & TKA & 10 od $^{\mathrm{a}}$ & 40 od $^{b}$ & $10-14$ & $10-14$ \\
\hline RECORD $4^{28}$ & TKA & 10 od $^{\mathrm{a}}$ & 30 bidc $^{c}$ & $10-14$ & $10-14$ \\
\hline
\end{tabular}

Notes: ${ }^{S}$ tarted 6-8 $\mathrm{h}$ after surgery (tablets); ' 'Started on the evening before surgery (injected subcutaneously); 'Started 12-24 h after surgery (injected subcutaneously). Abbreviations: THA, total hip arthroplasty; TKA, total knee arthroplasty; Riva, rivaroxaban; Enox, enoxaparin; OD, once daily; Bid, twice daily.
Table 3 Efficacy results of the RECORD studies

\begin{tabular}{|c|c|c|c|c|c|}
\hline \multirow[t]{2}{*}{ Study title } & \multirow[t]{2}{*}{$\begin{array}{l}\text { Rando- } \\
\text { mized } \\
\mathbf{N}\end{array}$} & \multicolumn{2}{|c|}{$\begin{array}{l}\text { Primary } \\
\text { efficacy } \\
\text { endpoint }^{\mathrm{a}} \%\end{array}$} & \multirow{2}{*}{$\begin{array}{l}\text { Relative } \\
\text { risk } \\
\text { reduction } \\
\%\end{array}$} & \multirow[t]{2}{*}{$\begin{array}{l}P \text {-value } \\
\text { for } \\
\text { difference }\end{array}$} \\
\hline & & riva. & enox. & & \\
\hline RECORD I 25 & $454 I$ & I.I & 3.7 & 70 & $<0.001$ \\
\hline RECORD $2^{26}$ & 2509 & 2.0 & 9.3 & 79 & $<0.001$ \\
\hline RECORD $3^{27}$ & 2531 & 9.6 & 18.9 & 49 & $<0.001$ \\
\hline RECORD $4^{28}$ & 3148 & 6.9 & 10.1 & 31 & 0.012 \\
\hline
\end{tabular}

Note: aPrimary efficacy endpoint was the composite of the incidence of any deep vein thrombosis (DVT) (proximal and/or distal), nonfatal symptomatic, objectively confirmed pulmonary embolism (PE) and all cause deaths.

Abbreviations: Riva, rivaroxaban; Enox, enoxaparin.

intracranial, intraocular, or intraspinal); bleeding requiring re-operation; and clinically overt extra-surgical-site bleeding associated with a fall in hemoglobin $\geq 2 \mathrm{~g} / \mathrm{dL}$ or requiring an infusion of $\geq 2$ units of blood or packed cells. Clinically relevant nonmajor bleeding, hemorrhagic wound complications, and other nonmajor bleeding events were among the other safety outcomes. Table 5 shows the incidence of major bleeding in the RECORD studies. There were no important differences between the groups. There were not any observed differences in action on the liver function when rivaroxaban was used for long-term prophylaxis in the RECORD 1 and RECORD 2 studies compared with short-term prophylaxis with rivaroxaban.

Some authors have claimed that the definition of major bleeding used in the RECORD program did not include surgical site bleedings, ${ }^{29,30}$ however, this is only partially correct as the clinically most important surgical site bleedings: fatal bleeding or reoperation due to bleeding were covered by the definition. Hemorrhagic wound complications and wound infections were reported separately. This has led to speculations about underestimation of the major bleeding rates in the RECORD studies. ${ }^{30,31}$ However, when major bleedings, nonmajor clinically relevant bleedings and surgical site bleedings were combined across all RECORD studies

Table 4 Symptomatic VTE events of the RECORD studies

\begin{tabular}{llll}
\hline Study title & \multicolumn{2}{l}{$\begin{array}{l}\text { Symptomatic VTE events } \\
\text { during treatment } \%\end{array}$} & \multirow{2}{*}{$\begin{array}{l}\text { P-value for } \\
\text { difference }\end{array}$} \\
\cline { 2 - 3 } & riva. & enox. & \\
\hline RECORD 126 & 0.3 & 0.5 & 0.22 \\
RECORD 2 & 0.2 & 1.2 & 0.004 \\
RECORD $3^{28}$ & 0.7 & 2.0 & 0.005 \\
RECORD $4^{29}$ & 0.7 & 1.2 & 0.19 \\
\hline
\end{tabular}

Notes: aSymptomatic venous thromboembolism (VTE) included any symptomatic DVT (proximal or distal) and non-fatal or fatal PE in patients in the safety population who had undergone surgery.

Abbreviations: Riva, rivaroxaban; Enox, enoxaparin. 
Table 5 Safety results of the RECORD studies

\begin{tabular}{|c|c|c|c|}
\hline \multirow[t]{2}{*}{ Study title } & \multicolumn{2}{|c|}{ Major bleeding $\%$} & \multirow{2}{*}{$\begin{array}{l}P \text {-value for } \\
\text { difference }\end{array}$} \\
\hline & riva. & enox. & \\
\hline RECORD $\left.\right|^{26}$ & 0.3 & 0.1 & 0.18 \\
\hline RECORD $2^{27}$ & 0.1 & 0.1 & NS \\
\hline RECORD $3^{28}$ & 0.6 & 0.5 & 0.77 \\
\hline RECORD $4^{29}$ & 0.7 & 0.3 & 0.11 \\
\hline
\end{tabular}

Notes: aprimary safety endpoint was the incidence of major bleeding (according to preset criteria) starting after the first postoperative dose of study drug, but no later than 2 days after the last dose of study drug.

Abbreviations: Riva, rivaroxaban; Enox, enoxaparin.

only a trend towards a lower bleeding rate with enoxaparin compared with rivaroxaban was seen $(1.37 \%$ versus $1.80 \%$; $P=0.063) .{ }^{31}$ The belief that bleeding rates obtained in one clinical study can be directly compared with bleeding rates in another study, as long as the same definitions are used, is a common misapprehension. Not just the use of anticoagulants but also a variety of other study-specific factors influence the final bleeding outcomes of a clinical study in terms of surgical approach, the skill of the participating surgeons, the type of implant used, the use of drains, perioperative use of antifibrinolytics, country-specific guidelines for the use of blood products, the availability of blood for transfusion and the surgeon's threshold for reporting a bleeding complication. Direct comparison of bleeding rates between various treatment options reported in different clinical, multi-center, studies conducted in different countries is therefore misleading. The only recommendable approach to assess the bleeding risk with an antithrombotic drug regimen is to compare the rates of bleeding in the treatment arms within the same study, on the condition that a double-blind design is used and all bleedings are adjudicated by an independent, blinded committee.

\section{Apixaban}

Apixaban (Bristol-Myers Squibb, New York, NY, USA) is an oral, direct FXa inhibitor and has been evaluated in a phase III study for the prevention of VTE after TKA (ADVANCE-1). Results from this study indicated that apixaban (2.5 mg twice daily [bid]) did not meet the pre-specified criteria for noninferiority compared with enoxaparin $(30 \mathrm{mg}$ bid) with respect to the primary efficacy endpoint; however, rates of major bleeding and nonmajor clinically relevant bleedings were significantly reduced with apixaban. ${ }^{32}$ The ADVANCE-2 study compared apixaban (2.5 mg bid) with enoxaparin (40 mg od) in patients undergoing TKA. ${ }^{33}$ The incidence of the primary endpoint was $15.1 \%$ and $24.4 \%$ for the apixaban and enoxaparin groups, respectively $(P<0.0001)$. Major VTE (a composite of proximal DVT, symptomatic nonfatal PE, and VTE-related death) occurred less frequently in the apixaban group (1.1\%) compared with the enoxaparin group $(2.2 \% ; P=0.019)$. Symptomatic VTE events and VTE related deaths occurred at an equal rate of $0.46 \%$ in the two groups. The major bleeding rate and the rate of clinically relevant nonmajor bleeding did not differ between the groups although there was a trend towards a lower incidence with apixaban. Apixaban $2.5 \mathrm{mg}$ bid has also been compared with enoxaparin (40 mg od) in patients undergoing THA in the ADVANCE-3 study which has been completed but is not yet reported.

\section{Other anticoagulants under development}

As shown in Table 1 several other oral, direct FXa inhibitors are in clinical development, including YM150, betrixaban and DU-176b ${ }^{36,38}$ (now called edoxaban). Their comparative efficacy and potential place in thromboprophylaxis after THA or TKA remains to be evaluated.

\section{A new parenterally administered compound under way}

A new hemisynthetic ultra-low-molecular-weight heparin (AVE5026) for the prevention of VTE after THA and TKA is also undergoing clinical development. ${ }^{38}$ The drug has a high anti-FXa activity and residual anti-FIIa activity. In a phase II dose ranging study patients undergoing TKA were treated with the following once-daily doses of AVE5026 injected subcutaneously: $5,10,20,40$, or $60 \mathrm{mg}$ or enoxaparin $40 \mathrm{mg}$ once-daily as a comparator. There was a significant dose response for prevention of VTE across the different doses ranging from $5.3 \%$ to $44.1 \%$ compared with $35.8 \%$ in the enoxaparin group. The VTE rate was high, but when compared with other contemporary TKA studies it was within the same range. ${ }^{38}$ There was also a significant dose response in terms of major bleeding and any bleeding. Based on this study it was decided that a dose of $20 \mathrm{mg}$ of AVE5026 was to be used in a large phase III program which is ongoing.

\section{Patient considerations}

Whether oral drug administration is more accepted by patients than administration by injection is a contention that is difficult to disprove, although it lacks positive supporting evidence. First of all this is only a real problem after discharge because nurses are readily available as long as the patients are in hospital. Bergqvist and Jonsson in 1999 reported that the cost-effectiveness of enoxaparin was reduced when the injections were to be administered by a 
home nurse, because patients were not able or willing to self-inject at home after hospital discharge. ${ }^{39}$ Poor compliance with oral ximelagatran (no longer available due to liver toxicity) has been reported previously in patients undergoing TKA with only $90 \%$ adherence to an 8 -day regimen. ${ }^{40}$ However, it is not possible to solve the dispute regarding the advantages of oral versus subcutaneous administration of anticoagulants based on existing data because patient behavior in a controlled clinical study cannot be compared with the real-life situation. XAMOS (Xa inhibition in the prophylaxis of post-surgical venous thromboembolism after elective major orthopedic surgery of hip or knee) is an ongoing post-marketing, noninterventional study comparing the efficacy and safety of rivaroxaban with various existing prophylactic regimens. The study is planned to involve 15,000 patients undergoing THA or TKA worldwide and is designed to evaluate how the new drug functions in a reallife setting including compliance issues.

Another aspect has been whether nausea and vomiting can negatively influence oral drug intake, which is at least a theoretical benefit to the injectable route, or whether the oral drug intake in the early postoperative period could cause these symptoms. This was the reason why the first oral antithrombotic regimen on the market, ximelagatran, was initiated by subcutaneous injection of melagatran for the first days after the operation followed by oral intake. ${ }^{42}$ There is not many data on compliance with oral antithrombotics; however, low incidences of nausea and vomiting were reported to be high in one of the phase II studies with rivaroxaban when the drug was administrated early postoperatively. ${ }^{42}$

The lack of an antidote for many of these new compounds has been criticized and noted as a potential risk. ${ }^{43}$ The relatively short half-life which enables a quick reversal of the anticoagulant effect after treatment cessation and a possibility to administer recombinant active factor VII or activated prothrombin complex concentrate is suggested in selected cases has been advised having administered rivaroxaban. ${ }^{43}$

Finally, an issue with implications to patients undergoing orthopedic procedures is the concern regarding the safety of new anticoagulants when used in combination with neuraxial anesthesia/analgesia. The basic recommendation is to wait two half-lives after intake of an anticoagulant drug before a central neuraxial block is performed and in the case of indwelling catheters these should be removed with the same time interval after intake. ${ }^{44}$ Because most of the new antithrombotic regimens are designed to start postoperatively this precaution is not a problem, except when epidural analgesia is used after an operation as this is still common practice in some countries.

\section{Conclusion}

With the convenience of oral, fixed dosing and no need for routine coagulation monitoring, the introduction of new anticoagulants into clinical practice may facilitate guideline adherence, particularly in the outpatient settings, in patients undergoing THA or TKA, and have the potential to improve overall clinical outcomes. In case all compounds that are currently in development finally reach the market it will be good news for both patients and health services as it will inevitably result in lower clinical costs. The situation was seen with LMWH in the 1990's where heavy competition between the various drug companies reduced the selling prices dramatically.

\section{Conflict of interest}

The author of this paper has received consultancy fees from Bayer Schering Pharma AG, Berlin, Germany, Bristol-Myers Squibb, New York, USA and Sanofi-Aventis, Paris, France.

\section{References}

1. Geerts WH, Bergqvist D, Pineo GF, et al. Prevention of venous thromboembolism: American College of Chest Physicians Evidence-Based Clinical Practice Guidelines (8th Edition). Chest. 2008;133 Suppl 6: 381S-453S.

2. Borris LC. Barriers to the optimal use of anticoagulants after orthopaedic surgery. Arch Orthop Trauma Surg. 2009;129:1441-1445.

3. American academy of orthopedic surgeons. The burden of musculoskeletal diseases in the United States 2008; Chapter 4: Arthritis and joint pain. Available at http://www.boneandjointburden.org Accessed Feb, 2010.

4. Virchow RLK. Gesammelte Abhandlungen zur Wissenschaftlichen Medicin. Frankfurt: Meidinger Sohn and Company; 1856.

5. Dahl OE, Johnsen H, Kierulf P, et al. Intrapulmonary thrombin generation and its relation to monomethylmethacrylate plasma levels during hip arthroplasty. Acta Anaesthesiol Scand. 1992;36:331-335.

6. Mann KG, Brummel K, Butenas S. What is all that thrombin for? J Thromb Haemost. 2003;1:1504-1514.

7. Mann KG, van Veer C, Cawtern K, et al. The role of the tissue factor pathway in inhibition of coagulation. Blood Coagul Fibrinolysis. 1998 9 Suppl 1:S3-S7.

8. Rauch U, Nemerson Y. Circulating tissue factor and thrombosis. Curr Opin Hamatol. 2000;7:273-277.

9. Mann KG, Butenas S, Brummel K. The dynamics of thrombin formation. Arterioscler Thromb Vasc Biol. 2003;23:17-25.

10. Samama MM, Gerotziafas GT. Evaluation of the pharmacological properties and clinical results of the synthetic pentasaccharide (fondaparinux). Thromb Res. 2003;109:1-11.

11. Perzborn E, Strassburger J, Wilmen A, et al. In vitro and in vivo studies of the novel antithrombotic agent BAY 59-7030 - an oral, direct factor Xa inhibitor. J Thromb Haemost. 2005;3:514-521.

12. Stangier J, Rathgen K, Stahle H, Gansser D, Roth W. The pharmacokinetics, pharmacodynamics and tolerability of dabigatran etexilate, a new oral direct thrombin inhibitor, in healthy male subjects. Br J Clin Pharmacol. 2007;64:292-303.

13. Summary of product characteristics Pradaxa 2009. Available at http:// www.ema.europa.eu/humandocs/PDFs/EPAR/pradaxa/emea-combinedh829en.pdf. Accessed Jan, 2010. 
14. Eriksson BI, Dahl OE, Rosencher N, et al. Dabigatran etexilate versus enoxaparin for prevention of venous thromboembolism after total hip replacement: a randomised, double-blind, non-inferiority trial. Lancet. 2007;370:949-956.

15. Eriksson BI, Dahl OE, Rosencher N, et al. RE-MODEL Study Group. Oral dabigatran etexilate vs subcutaneous enoxaparin for the prevention of venous thromboembolism after total knee replacement: the REMODEL randomized trial. J Thromb Haemost. 2007;5:2178-2185.

16. Ginsberg J, Davidson B, Comp P, et al. The oral thrombin inhibitor dabigatran etexilate versus the North American enoxaparin regimen for the prevention of venous thromboembolism after knee arthroplasty surgery. J Arthroplasty. 2008;24:1-9.

17. Perzborn E, Strassburger J, Wilmen A, et al. In vitro and in vivo studies of the novel antithrombotic agent BAY 59-7939 - an oral, direct Factor Xa inhibitor. J Thromb Haemost. 2005;3:514-521.

18. Kubitza D, Becka M, Voith B, Zuehlsdorf M, Wensing G. Safety, pharmacodynamics, and pharmacokinetics of single doses of BAY 59-7939, an oral, direct factor Xa inhibitor. Clin Pharmacol Ther. 2005;78:412-421.

19. Kubitza D, Becka M, Roth A, Mueck W. Dose-escalation study of the pharmacokinetics and pharmacodynamics of rivaroxaban in healthy elderly subjects. Curr Med Res Opin. 2008;24:2757-2765.

20. Kubitza D, Becka M, Zuehlsdorf M, Mueck W. No interaction between the novel, oral direct Factor Xa inhibitor BAY 59-7939 and digoxin. J Clin Pharmacol. 2006;46:Abstract \#11.

21. Kubitza D, Becka M, Zuehlsdorf M, Mueck W. Effect of food, an antacid, and the $\mathrm{H} 2$ antagonist ranitidine on the absorption of BAY 59-7939 (rivaroxaban), an oral, direct Factor Xa inhibitor, in healthy subjects. J Clin Pharmacol. 2006;46:549-558.

22. Kubitza D, Becka M, Mueck W, Zuehlsdorf M. Safety, tolerability, pharmacodynamics, and pharmacokinetics of rivaroxaban - an oral, direct Factor Xa inhibitor - are not affected by aspirin. J Clin Pharmacol. 2006;46:981-990.

23. Summary of product characteristics Xarelto 2010. Available at http:// www.ema.europa.eu/humandocs/Humans/EPAR/xarelto/xarelto. Accessed Mar, 2010.

24. Eriksson BI, Borris LC, Dahl OE, et al. ODIXa-HIP Study Investigators. A once-daily, oral, direct Factor Xa inhibitor, rivaroxaban (BAY 59-7939), for thromboprophylaxis after total hip replacement. Circulation. 2006;114(2374);2313-2316.

25. Eriksson BI, Borris LC, Friedman RJ, et al. RECORD1 Study Group. Rivaroxaban versus enoxaparin for thromboprophylaxis after hip arthroplasty. N Engl J Med. 2008;358:2765-2775.

26. Kakkar AK, Brenner B, Dahl OE, et al. Extended duration rivaroxaban versus short-term enoxaparin for the prevention of venous thromboembolism after total hip arthroplasty: a double-blind, randomised controlled trial. Lancet. 2008;372:31-39.

27. Lassen MR, Ageno W, Borris LC, et al. Rivaroxaban - an oral, direct Factor Xa inhibitor - for the prevention of venous thromboembolism after total knee arthroplasty. $N$ Engl J Med. 2008;358:2776-2786.

28. Turpie AGG, Lassen MR, Davidson BL, et al. For the RECORD4 investigators. Rivaroxaban versus enoxaparin for thromboprophylaxis after total knee arthroplasty (RECORD4):a randomized trial. Lancet. 2009;373:1673-1680
29. Merli G, Spyropoulos AC, Caprini JA. Use of emerging oral anticoagulants in clinical practice. Translating results from clinical trials to orthopedic and general surgical patient populations. Ann Surg. 2009; 250:219-228.

30. Hull RD, Yusen RD, Bergqvist D. Assessing the safety profiles of new anticoagulants for major orthopedic surgery thromboprophylaxis. Clin Appl Thromb Haemost. 2009;15:377-388.

31. Van Thiel D, Kalodiki E, Wahi R, Litinas E, Haque W, Rao G. Interpretation of benefit-risk of enoxaparin as comparator in the RECORD program; rivaroxaban oral tablets $(10 \mathrm{mg})$ for use in prophylaxis in deep vein thrombosis and pulmonary embolism in patients undergoing hip or knee replacement surgery. Clin Appl Thromb Haemost. 2009;15:389-399.

32. Lassen M, Gallus A, Pineo G, et al. Randomized double-blind comparison of apixaban with enoxaparin for thromboprophylaxis after knee replacement: the ADVANCE-1 trial. Blood (ASH Annual Meeting Abstracts). 2008;112:31.

33. Lassen MR, Raskob GE, Gallus A, et al. Apixaban versus enoxaparin for thromboprophylaxis after knee replacement (ADVANCE-2): a randomized double-blind trial. Lancet. 2010;375:807-815.

34. Shantsila E, Lip GY. Apixaban, an oral, direct inhibitor of activated Factor Xa. Curr Opin Investig Drugs. 2008;9:1020-1033.

35. Raghavan N, Frost CE, Yu Z, et al. Apixaban metabolism and pharmacokinetics following oral administration to humans. Drug Metab Dispos. 2008;37:74-81.

36. Eriksson BI, Turpie AG, Lassen MR, et al. Prevention of venous thromboembolism with an oral Factor Xa inhibitor, YM150, after total hip arthroplasty. A dose finding study (ONYX-2). J Thromb Haemost. 2010;8(4):714-721.

37. Turpie AGG, Bauer KA, Davidson BA, et al. A randomized evaluation of betrixaban, an oral factor Xa inhibitor, for prevention of thromboembolic events after total knee replacement (EXPERT). Thromb Haemost. 2009;101:68-76.

38. Lassen MR, Dahl OE, Mismetti P, Destrée D, Turpie AGG. AVE5026, a new hemisynthetic ultra-low-molecular-weight heparin for the prevention of venous thromboembolism in patients after total knee replacement surgery - TREK: a dose-ranging study. J Thromb Haemost. 2009;7: 566-572.

39. Bergqvist D, Jonsson B. Cost-effectiveness of prolonged administration of a low molecular weight heparin for the prevention of deep venous thrombosis following hip replacement. Value Health. 1999; 2:288-294.

40. Francis CW, Davidson BL, Berkowitz SD, et al. Ximelagatran versus warfarin for the prevention of venous thromboembolism after total knee arthroplasty:a randomized, double-blind trial. Ann Intern Med. 2002; 137;648-655.

41. Eriksson BI. Clinical experience of melagatran/ximelagatran in major orthopaedic surgery. Thromb Res. 2003;109:S23-S29.

42. Turpie AGG, Fisher WD, Bauer KA, et al. BAY 59-7939:an oral, direct Factor Xa inhibitor for the prevention of venous thromboembolism in patients after total knee replacement. A phase II dose-ranging study. J Thromb Haemost. 2005;3:2479-2486.

43. Lippi G, Franchini M, Targher G. Rivaroxaban for thromboprophylaxis. N Engl J Med. 2008;359:2174-2176.

44. Rosencher N, Bonnet MP, Sessler DI. Selected new antithrombotic agents and neuraxial anaesthesia for major orthopaedic surgery: management strategies. Anaesthesia. 2007;62:1154-1160.
Journal of Blood Medicine

\section{Publish your work in this journal}

The Journal of Blood Medicine is an international, peer-reviewed, open access, online journal publishing laboratory, experimental and clinical aspects of all topics pertaining to blood based medicine including but not limited to: Transfusion Medicine; Blood collection, Donor issues, Transmittable diseases, and Blood banking logistics; Immunohematology; Artificial and alternative

blood based therapeutics; Hematology; Biotechnology/nanotechnology of blood related medicine; Legal aspects of blood medicine; Historical perspectives. The manuscript management system is completely online and includes a very quick and fair peer-review system. Visit http://www.dovepress.com/ testimonials.php to read real quotes from published authors.

\section{Dovepress}

Submit your manuscript here: http://www.dovepress.com/Journal-of-blood-medicine-journal 